\title{
Trends in On-Road Vehicle Emissions of Ammonia
}

\author{
A.J. Kean ${ }^{1}$, D. Littlejohn ${ }^{2}$, G.A. Ban-Weiss ${ }^{3}$, R.A. Harley ${ }^{4}$, T.W. Kirchstetter ${ }^{2}$, and M.M \\ Lunden $^{2}$ \\ ${ }^{1}$ Mechanical Engineering Dept., California Polytechnic State University, San Luis Obispo, CA. \\ ${ }^{2}$ Environmental Energy Technologies Division, Lawrence Berkeley National Laboratory, \\ Berkeley, CA 94720 \\ ${ }^{3}$ Mechanical Engineering Dept., University of California, Berkeley, CA 94720 \\ ${ }^{4}$ Civil and Environmental Engineering Dept., University of California, Berkeley, CA 94720
}

\begin{abstract}
Motor vehicle emissions of ammonia have been measured at a California highway tunnel in the San Francisco Bay area. Between 1999 and 2006, light-duty vehicle ammonia emissions decreased by $38 \pm 6 \%$, from $640 \pm 40$ to $400 \pm 20 \mathrm{mg} \mathrm{kg}^{-1}$. High time resolution measurements of ammonia made in summer 2001 at the same location indicate a minimum in ammonia emissions correlated with slower-speed driving conditions. Variations in ammonia emission rates track changes in carbon monoxide more closely than changes in nitrogen oxides, especially during later evening hours when traffic speeds are highest. Analysis of remote sensing data of Burgard et al. (Environ Sci. Technol. 2006, 40, 7018-7022) indicates relationships between ammonia and vehicle model year, nitrogen oxides, and carbon monoxide. Ammonia emission rates from diesel trucks were difficult to measure in the tunnel setting due to the large contribution to ammonia concentrations in a mixed-traffic bore that were assigned to light-duty vehicle emissions. Nevertheless, it is clear that heavy-duty diesel trucks are a minor source of ammonia emissions compared to light-duty gasoline vehicles.
\end{abstract}




\section{Introduction}

The use of catalytic converters has dramatically reduced most pollutant emissions from motor vehicles. Catalytic converters make use of the low activation energy of certain heterogeneous reactions on rare earth metals (e.g., palladium, platinum, and rhodium) to speed reactions in their approach to equilibrium conditions. Starting in 1975, oxidation mode (i.e, twoway) catalytic converters were introduced on automobiles in the U.S. (Heavenrich et al., 1987). These converters oxidize carbon monoxide $(\mathrm{CO})$ and volatile organic compounds (VOC) to carbon dioxide $\left(\mathrm{CO}_{2}\right)$ and water. In 1981, three-way catalytic converters were introduced, with the additional capability to reduce nitrogen oxides $\left(\mathrm{NO}_{\mathrm{x}}=\mathrm{NO}+\mathrm{NO}_{2}\right)$ to nitrogen gas. Having both oxidizing and reducing conditions occur simultaneously on the catalyst surface is best achieved if the air/fuel mixture is stoichiometric (Heywood, 1988). This is because hydrogen $\left(\mathrm{H}_{2}\right)$, the reducing agent for $\mathrm{NO}$, and oxygen $\left(\mathrm{O}_{2}\right)$, the oxidizing agent for $\mathrm{CO}$ and VOC, can only be maintained in exhaust at sufficient concentrations by closely modulating air/fuel ratio around stoichiometric conditions. Feedback control of the air/fuel ratio using exhaust oxygen sensors was implemented in new vehicles starting in the 1980s to maintain near-stoichiometric operating conditions for optimum three-way catalytic converter operation.

An unwanted side effect of the use of three-way catalytic converters has been an increase in ammonia $\left(\mathrm{NH}_{3}\right)$ emissions from motor vehicles. Ammonia is the primary alkaline gas and the third most common nitrogen-containing species in the atmosphere, after nitrogen gas and nitrous oxide (Seinfeld and Pandis, 1998). Ammonia reacts with sulfuric or nitric acid in the atmosphere to generate secondary particles of ammonium sulfate and ammonium nitrate, respectively. Ammonia also is a major contributor to acidification/eutrophication processes in lakes (Pearson and Stewart, 1993; Watson et al., 1994). 
Until recently, motor vehicles were not recognized to be a significant source of ammonia. However, the U.S. EPA now estimates that $5 \%$ of national ammonia emissions are due to motor vehicles, with almost all the remaining ammonia coming from agricultural processes (EPA, 2003). This figure may understate the importance of motor vehicle emissions in urban areas where agricultural sources of ammonia are mostly absent. To date, no significant regulatory effort has been made to control $\mathrm{NH}_{3}$ emissions from motor vehicles.

Ammonia is not created in significant quantities during typical combustion in a gasolinepowered vehicle, but is an undesirable product of NO reduction on the catalyst surface. Overreduction of $\mathrm{NO}$ - beyond the formation of molecular $\mathrm{N}_{2}$ - leads to ammonia in motor vehicle exhaust. Consequently, $\mathrm{NH}_{3}$ emissions were low for early 1980s and older gasoline-powered vehicles (Pierson and Brachaczek, 1983) and have since increased following the widespread use of three-way catalytic converters (Cadle et al., 1979, Moeckli et al., 1996, Fraser and Cass, 1998, Kean et al., 2000).

On-road measurements of ammonia emissions from motor vehicles have been reported previously by several groups of investigators. Early studies showed that ammonia emissions from light-duty vehicles were low (Pierson and Brachaczek, 1983). These measurements were made in the Allegheny Mountain Tunnel in Pennsylvania in 1981 when less than $10 \%$ of vehicles were equipped with three-way catalytic converters. Fraser and Cass (1998) and others (see Table 1) showed increased ammonia emissions following the widespread use of 3-way catalytic converters. Burgard et al. (2006a) used remote sensing to show that the distribution of ammonia emissions across the vehicle fleet shows an atypical pattern: the highest average ammonia emission rates were observed for $\sim 10$ year-old vehicles. It is well understood that the oldest vehicles (no catalytic converter) or those with deactivated catalysts will have negligible 
emissions of ammonia. In addition, Burgard et al. have shown that new vehicles also emit low quantities of ammonia. So unlike most other pollutants, ammonia emissions are dominated by “middle-aged" vehicles (Burgard et al., 2006a).

Ammonia emissions from catalyst-equipped vehicles have been shown in laboratory dynamometer studies to be markedly higher than for non-catalyst-equipped vehicles (Cadle et al., 1979; Urban and Garbe, 1979; Cadle and Mulawa, 1980; Durbin et al., 2002). The reaction that produces ammonia on the catalyst is enhanced if the engine runs fuel-rich, because that condition favors reducing processes on the catalyst surface (Cadle et al., 1979; Urban and Garbe, 1979; Cadle and Mulawa, 1980). Durbin et al. (2002) reported an average ammonia emission factor of $34 \mathrm{mg} \mathrm{km}^{-1}$ for 39 recruited gasoline-powered vehicles on the Federal Test Procedure (FTP), with increased ammonia emissions on more aggressive driving cycles. In related efforts, Huai et al. (2003 and 2005) showed that ammonia emissions are primarily generated during acceleration events for modern technology vehicles. Recent laboratory dynamometer studies also showed that vehicles equipped with more advanced emissions control technologies demonstrated better ammonia emission control behavior (Durbin et al., 2002; Huai et al., 2003 and 2005).

The primary objective of the present investigation was to determine if on-road emissions of ammonia are continuing to increase as turnover in the vehicle fleet continues to replace older vehicles whose catalysts may no longer be functional with new three-way catalyst-equipped vehicles. We have previously reported ammonia measurements from a large sample of on-road vehicles using California reformulated gasoline in 1999 (Kean et al., 2000), which are compared here to more recent measurements performed in 2006. We also present time-resolved ammonia measurements from 2001 to describe emissions as a function of vehicle speed and engine load. 
A secondary objective of this study was to estimate ammonia emissions from heavy-duty diesel vehicles. Ammonia emissions from heavy-duty vehicles have been shown to be small relative to modern light-duty vehicles (Pierson and Brachaczek, 1983; Burgard et al., 2006b). To meet increasingly stringent nitrogen oxide emission standards, future adoption of selective catalytic reduction (SCR) by the addition of urea or ammonia to diesel exhaust is likely. If not properly controlled, use of SCR could result in elevated ammonia emissions from heavy-duty vehicles. The present study documents baseline heavy-duty diesel truck ammonia emission rates prior to SCR use.

\section{Experimental Section}

\section{Field Sampling Site}

The Caldecott tunnel is located on highway 24 just east of Berkeley, CA in the San Francisco Bay area. It consists of three bores, each consisting of two traffic lanes. The tunnel is $970 \mathrm{~m}$ long on a $4.1 \%$ grade uphill in the eastbound direction. This study focuses on bore 1 , which contains a mix of light and heavy-duty traffic, and bore 2, which contains almost entirely light-duty traffic. The traffic direction through bore 2 is changed around midday to accommodate the dominant rush-hour travel direction. For this study, however, we consider only times when traffic is headed eastbound (uphill).

\section{$\underline{\text { Pollutant Measurements }}$}

For all years of this study $\left(1999,2001\right.$, and 2006), $\mathrm{NO}_{\mathrm{x}}, \mathrm{CO}$, and $\mathrm{CO}_{2}$ concentrations were measured at the tunnel inlet and outlet on summer weekdays using standard ambient air monitoring equipment (Kean et al., 2000; Ban-Weiss et al., 2008). Sample air was drawn from the traffic bore and calibration of all gas-phase analyzers was checked daily prior to sampling for 
all years. Ammonia measurements at the inlet and outlet of the traffic bore were made in 1999 on 8 summer weekdays between 4 and 6 PM PDT, using annular denuders coated with citric acid, with extracts later analyzed using ion chromatography with a conductivity detector (Kean et al., 2000).

In 2001, semi-continuous measurements of gas-phase ammonia were made with 15minute time resolution at the exit of tunnel bore 2 between 2:00 and 9:30 PM on 7 days in July and August. Ammonia was stripped from the sample air stream by dissolution in a water film in cocurrent flow inside a tubular wet effluent denuder (Buhr, 1995; Fischer et al., 2003), as shown in Figure 1. Sample air was drawn from the exhaust bore (located directly above the traffic bore) into a pre-cleaned $70 \mathrm{~cm}$ long, $0.4 \mathrm{~cm}$ ID etched borosilicate glass tube. The air flow rate was controlled at $1.06 \mathrm{~L} \mathrm{~min}^{-1}$ using a critical orifice. Deionized water was supplied to the top of the denuder by a peristaltic pump at a rate of $1.7 \mathrm{~mL} \mathrm{~min}^{-1}$. The water flowed down the inner walls of the denuder tube and ammonia gas diffused towards and dissolved in the flowing film of water. Collection efficiencies were measured during instrument development and found to be close to unity. The water was collected at the bottom of the tube using a collection cup and drain attached to the bottom of the denuder tube. A second peristaltic pump conveyed the collected water to a cation concentrator column that collected sample for 13 minutes. From the concentrator column, the sample was sent to an ion chromatograph for quantification of ammonium. Calibration of the signal was accomplished with aqueous solutions of known ammonium concentration (Fischer et al., 2003). In 2001, only the tunnel exit ammonia concentration was measured. Based on experience from 1999 and 2006, background levels of ammonia are small $\left(\sim 24 \mu \mathrm{g} \mathrm{m}^{-3}\right)$ and relatively constant compared to those measured at the tunnel exit. 
In 2006, 2-hour average ammonia measurements were made on 8 days in bore 2 (lightduty vehicles only), and on 8 days in bore 1 (mixed traffic including both light-duty vehicles and heavy-duty diesel trucks). Measurements in bore 2 were made during the 4-6 PM peak traffic period. Measurements in bore 1 were performed from 12-2 PM, when the heavy-duty traffic contribution to emissions was highest. Samples from the inlet and outlet of the traffic bores were collected on citric acid-coated annular denuders at a nominal flow rate of $5 \mathrm{~L} \mathrm{~min}^{-1}$. Flow was regulated using a critical orifice and quantified with a primary air flow standard. The ammonium collected on the denuders was analyzed after each day of sampling using an ion chromatograph with conductivity detector, similar to 1999 (Kean et al., 2000). Traffic volume and average speed through the tunnel were determined for each sampling day, as detailed elsewhere (Ban-Weiss et al., 2008).

\section{Results and Discussion}

Light-duty Ammonia Emission Factor Trends Between 1999 and 2006

Light-duty vehicle emission factors were calculated by carbon balance using equation 1

$$
E_{\mathrm{NH}_{3}}=\left(\frac{\Delta\left[\mathrm{NH}_{3}\right]}{\Delta\left[\mathrm{CO}_{2}\right]+\Delta[\mathrm{CO}]}\right) w_{C}
$$

where $E_{\mathrm{NH} 3}$ is the ammonia emission factor ( $\mathrm{mg} \mathrm{kg}^{-1}$ of fuel burned), $\Delta\left[\mathrm{NH}_{3}\right]$ is the increase in mass concentration of ammonia measured between tunnel entrance and exit $\left(\mu \mathrm{g} \mathrm{m}^{-3}\right), \Delta\left[\mathrm{CO}_{2}\right]$ and $\Delta[\mathrm{CO}]$ are similarly background-subtracted concentrations $\left(\mathrm{mg} \mathrm{C} \mathrm{m}{ }^{-3}\right)$, and $w_{C}=0.85$ is the mass fraction of carbon in oxygenated gasoline used in California. Organic compounds are not included in the denominator of eq. 1 because the hydrocarbon contribution to total carbon concentrations in the tunnel is known to be negligible compared to $\mathrm{CO}_{2}$ and $\mathrm{CO}$. 
The ammonia emission factor for light-duty vehicles at the Caldecott tunnel in 1999 was $640 \pm 40 \mathrm{mg} \mathrm{kg}^{-1}$. The uncertainty bounds provide a $95 \%$ confidence interval for the mean based on run-to-run variability in the results over 8 days of sampling. At the time of these measurements, we estimated based on a license-plate survey that $\sim 99 \%$ of vehicles in the center bore are gasoline-powered and $>94 \%$ of the vehicles were originally outfitted with three-way catalyst systems (Kean et al., 2000). During the rush-hour period of measurement, driving conditions and the mean vehicle age ( $\sim 6$ years old) at the Caldecott Tunnel are consistent from year to year (Kirchstetter et al., 1999; Ban-Weiss et al., 2008).

The ammonia emission factor in 2006 decreased to $400 \pm 20 \mathrm{mg} \mathrm{kg}^{-1}$. This represents a $38 \pm 6 \%$ reduction over the 7 years since the 1999 study (Kean et al., 2000). For comparison, over this same time period, the light-duty vehicle $\mathrm{NO}_{\mathrm{x}}$ emission factor for $\mathrm{NO}_{\mathrm{x}}$ decreased by 54 $\pm 6 \%$. The present study clarifies that despite increasing ammonia emissions as a given vehicle ages, the Caldecott tunnel fleet as a whole is emitting less ammonia today than 7 years ago under the same driving conditions.

In 1999, the molar ratio of ammonia to total fixed nitrogen (taken to be $\mathrm{NO}_{\mathrm{x}}+\mathrm{NH}_{3}$ ) in vehicle emissions was $0.21 \pm 0.01$ at the Caldecott tunnel. This same measurement in 2006 was $0.27 \pm 0.01$. While vehicle emission rates (and total emissions) of ammonia are reducing over time, the fraction of reactive nitrogen being emitted as ammonia by light-duty vehicles is increasing. This is a consequence of greater focus on controlling $\mathrm{NO}_{\mathrm{x}}$ emissions compared to efforts to reduce ammonia emissions.

A comparison of the Caldecott tunnel results to other on-road and dynamometer-based investigations is given in Table 1. Where possible, emission factors have been converted into the same units to facilitate comparison. An estimate of ammonia emission factors at the Caldecott 
tunnel on a mg km${ }^{-1}$ basis can be made using vehicle fuel efficiencies measured at the Caldecott tunnel in 2001 (Kean et al., 2003). During the 4-6 PM traffic period in 2001, the measured lightduty vehicle fuel consumption for uphill traffic was $16.4 \pm 0.1 \mathrm{~L} / 100 \mathrm{~km}(14.4 \pm 0.1 \mathrm{mpg})$. As fuel economies (EPA, 2006) and driving conditions at the tunnel (Ban-Weiss et al., 2008) have not changed significantly over the last decade, it is reasonable to apply this rate of fuel consumption to both the 1999 and 2006 measurements. Focusing on the Table 1 studies performed in California, it appears that early three-way catalyst fleets and modern fleets at high load emit over $600 \mathrm{mg} \mathrm{kg}^{-1}$ of ammonia. Modern fleets at lower loads emit lower rates of ammonia (350-450 $\mathrm{mg} \mathrm{kg}^{-1}$ ). The general similarity of the fuel-based measurements is notable given the wide range of measurement techniques used and driving conditions observed.

\section{$\underline{\text { Engine-Load Effects on Light-duty Ammonia Emissions }}$}

The wet-effluent denuder at the Caldecott Tunnel in 2001 permitted measurement of ammonia concentrations at 15-minute intervals over seven days of the study. Figure 2 presents the normalized ammonia emission factors $( \pm 95 \%$ confidence interval) over the course of the afternoons with uphill driving in summer 2001. These data have been normalized by the average emission factor measured from 4-6 PM, the period emphasized elsewhere in this investigation. Absolute emission factors are not presented because the ammonia measurements in 2001 were made in the exhaust bore (above the traffic bore), whereas the other gas-phase measurements where made in the traffic bore. There is a small pollutant concentration gradient from the traffic bore to the exhaust bore, which biases the numerator of eq. 1 low relative to the denominator when calculating absolute emission factors. In Figure 2, the normalized emission factor decreases gradually from 2 to 6 PM and then increases rapidly to a maximum at 9:30 PM. Also included in the figure are vehicle speeds through the tunnel in 2001 (Kean et al., 2003). The 
increase in ammonia emissions with increasing vehicle speed and thus engine load is apparent, as we have previously reported for $\mathrm{CO}$ and $\mathrm{NO}_{\mathrm{x}}$ (Kean et al., 2003).

Variations over the course of the afternoon in the ammonia emission factor during the entire 2001 study are compared to variations in $\mathrm{CO}$ and $\mathrm{NO}_{\mathrm{x}}$ in Figure 3. Ammonia roughly tracks $\mathrm{NO}_{\mathrm{x}}$ from 2-6 $\mathrm{PM}$, resulting in a near constant $\mathrm{NH}_{3}$ to fixed nitrogen ratio during this period. This may suggest that the quantity of $\mathrm{NO}_{\mathrm{x}}$ passing through the catalytic converters is limiting ammonia emissions. After 6 PM when traffic volumes are lower and vehicle speeds are higher, $\mathrm{NH}_{3}$ tracks $\mathrm{CO}$ emissions. Taking elevated $\mathrm{CO}$ emissions as an indication of enrichment, the more strongly reducing conditions on the catalyst appear to convert a greater fraction of $\mathrm{NO}_{\mathrm{x}}$ to ammonia during the period after 6 PM. The ratio of ammonia emissions to total fixed nitrogen emissions therefore increases.

Analysis of Remote Sensing Data

The above analysis pertains to fleet-average emissions. It is unclear from the tunnel data how ammonia emission rates are distributed across individual vehicles, and how they correlate with $\mathrm{NO}_{\mathrm{x}}$ and $\mathrm{CO}$ emission rates. Since most emitted $\mathrm{NH}_{3}$ molecules likely existed as $\mathrm{NO}$ molecules upstream of the catalytic converter, a trade-off is likely to exist such that high ammonia emissions occur at low NO emissions. In addition, high NO emissions may indicate lean combustion, which can hinder formation of ammonia on the catalyst.

The likely correlation between ammonia and CO emissions is less obvious. High CO emissions are an indication of strongly reducing conditions on the catalyst surface, which promotes conversion of $\mathrm{NO}$ to $\mathrm{NH}_{3}$. However under fuel-rich conditions, $\mathrm{NO}$ formation is limited, which in turn could limit formation of $\mathrm{NH}_{3}$ by the catalytic converter. Because of these conflicting effects, it is difficult to predict in advance if high ammonia and $\mathrm{CO}$ emissions occur 
concurrently. The picture is further complicated by the fact that elevated NO and/or CO emissions may be an indication of a non-functional catalyst, in which case low ammonia emissions would be expected. Remote sensing measurements of ammonia emissions reported by Burgard et al. (2006a) are used here to study relationships among pollutants. Measurements of $\mathrm{NH}_{3}, \mathrm{NO}$, and $\mathrm{CO}$ concentrations in the exhaust plumes of 21,858 individual vehicles were made by Burgard et al. in 2005 in Tulsa and Denver.

Figure 4 presents average ammonia emission factors $\left(\mathrm{mg} \mathrm{kg}^{-1}\right)$ as a function of $\mathrm{NO}$ and $\mathrm{CO}$ concentration in light-duty vehicle exhaust. For this, vehicles are binned based on their NO and $\mathrm{CO}$ exhaust concentrations, and then the average ammonia emission factor within each bin is presented. The average ammonia emission factors are: $610 \pm 30 \mathrm{mg} \mathrm{kg}^{-1}$ for model year 1995 and older vehicles (Figure 4a), $600 \pm 20 \mathrm{mg} \mathrm{kg}^{-1}$ for model year 1996-2000 (Figure 4b), $370 \pm 20 \mathrm{mg}$ $\mathrm{kg}^{-1}$ for model year 2001 and newer vehicles (Figure 4c), and $500 \pm 10 \mathrm{mg} \mathrm{kg}^{-1}$ for the entire fleet. The number of vehicles in each bin varies depending on the prevalence of the corresponding emission rates and is presented in the figures; less statistical significance should be given to bins with fewer vehicles.

Looking at Figure 4, ammonia emission factors are highest for vehicles with low exhaust NO concentrations and high exhaust CO concentrations. This trend is present for the three vehicle age groups, but is most pronounced for newer vehicles. The data suggest that there is a trade-off in the emissions of ammonia and NO; NO emissions decrease due to the formation of $\mathrm{NH}_{3}$ on the catalyst. The data also suggest that chemically reducing conditions on the catalyst surface (as evidenced by high $\mathrm{CO}$ ) do, in fact, enhance additional conversion of $\mathrm{NO}$ to $\mathrm{NH}_{3}$.

Figure 4 is useful for understanding correlations between ammonia and other pollutant emissions, but does not aid in understanding which vehicles are responsible for the bulk of total 
ammonia emissions at the measurement sites. Figure 5 estimates the contribution of each NO-CO bin to total ammonia emissions by accounting for the fact that the number of vehicles in each bin varies. For Figure 5, each ammonia emission factor in Figure 4 was weighted by the number of vehicles in that bin and then divided by the total emissions across the fleet. The results in Figure 5 should be considered approximate because its development effectively required assuming a constant fuel-economy value across the fleet. The model year 1995 and older vehicles were 19\% of the fleet and emit $23 \%$ of the total ammonia emissions, model year 1996-2000 vehicles were $36 \%$ of the fleet and emit $43 \%$ of emissions, and model year 2001 and newer vehicles were $45 \%$ of the fleet and emit $~ 34 \%$ of ammonia emissions. Further inspection of Figure 5 indicates that total emissions of ammonia are dominated by the vehicles with the lowest $\mathrm{NO}$ emissions. For the oldest vehicles, the bins with high ammonia emission factors (see Figure 4a) also contributed significantly to total ammonia emissions. This is in contrast to the newest vehicles, where several bins with high emission factors contributed insignificantly to total emissions because of the small number of vehicles in those bins. For the newest vehicles, a low emission factor for ammonia for the cleanest vehicles (i.e., low $\mathrm{NO}$ and low $\mathrm{CO}$ ) was overwhelmed by the sheer number of vehicles in this bin.

Ammonia Emissions from Medium- and Heavy-Duty Diesel Trucks

Contributions to ammonia concentrations in bore 1 of the Caldecott tunnel from mediumand heavy-duty (MD/HD) vehicles were estimated using $\mathrm{CO}_{2}$ as a tracer for gasoline engine emissions, together with $\mathrm{LD}$ vehicle emission ratios measured in bore 2 (see Ban-Weiss et al., 2008):

$$
\Delta\left[\mathrm{NH}_{3}\right]_{1, D}=\Delta\left[\mathrm{NH}_{3}\right]_{1}-\Delta\left[\mathrm{CO}_{2}\right]_{1, G}\left(\frac{\Delta\left[N \mathrm{HH}_{3}\right]_{2}}{\Delta\left[C \mathrm{O}_{2}\right]_{2}}\right)
$$


where subscripts 1 and 2 outside the bracket refers to tunnel bore number and D or G refers to emissions due to diesel or gasoline vehicles, respectively. $\Delta\left[\mathrm{CO}_{2}\right]_{1, \mathrm{G}}$ is calculated as:

$$
\frac{\Delta\left[\mathrm{CO}_{2}\right]_{1, D}}{\Delta\left[\mathrm{CO}_{2}\right]_{1}}=\frac{\rho_{D} w_{D}\left(f_{h d} U_{h d}+f_{m d} F U_{m d D}\right)}{\rho_{D} w_{D}\left(f_{h d} U_{h d}+f_{m d} F U_{m d D}\right)+\rho_{G} w_{G}\left(f_{l d} U_{l d}+f_{m d}(1-F) U_{m d G}\right)}
$$

and

$$
\Delta\left[\mathrm{CO}_{2}\right]_{1, G}=\Delta\left[\mathrm{CO}_{2}\right]_{1}-\Delta\left[\mathrm{CO}_{2}\right]_{1, D}
$$

where $f_{x}$ are the observed fractions of vehicles that are LD, MD, and HD in the tunnel and $\mathrm{F}=0.53$ is the fraction of MD vehicles equipped with diesel engines. Fuel densities $(\rho)$, carbon mass fractions (w), and fuel economies (U) are from Ban-Weiss et al. (2008). Once pollutant concentrations in bore 1 were apportioned between gasoline and diesel contributions, calculation of diesel truck emission factors proceeded via carbon balance using eq. 1 with $w_{C}=0.87$. The resulting ammonia emission factor for diesel trucks in the Caldecott tunnel in 2006 is $170 \pm 150$ $\mathrm{mg} \mathrm{kg}^{-1}$. The $95 \%$ confidence interval is large because diesel trucks do not appear to be major emitters of ammonia (Burgard et al., 2006b) and the observed fraction of diesel trucks in the Caldecott tunnel is small. For these reasons, the fraction of ammonia emissions attributed to diesel engines in bore 1 was only $8 \%$ on average. For comparison to the diesel truck ammonia emission factor, the light-duty vehicle emission factor for ammonia in the same year was $400 \pm$ $20 \mathrm{mg} \mathrm{kg}^{-1}$. The large uncertainty for the diesel value makes a definitive comparison of these two emission factors difficult. Given other recent measurements (Burgard et al., 2006b), it is likely that the true ammonia emission factor for diesel trucks lies at the low end of the range reported here. The Caldecott tunnel was not well-suited to determination of ammonia emission rates for diesel trucks, due to the large contribution to ammonia concentrations in bore 1 from light-duty vehicles. However, our results imply that diesel trucks are at present a minor source of ammonia emissions compared to light-duty gasoline vehicles. 


\section{Acknowledgments}

The submitted manuscript has been authored by a contractor of the U.S.Government under contract No. DE-AC02-05CH11231. Accordingly, the U.S. Government retains a nonexclusive royalty-free license to publish or reproduce the published form of this contribution, or allow others to do so, for U.S. Government purposes.

This project was funded by the California Air Resources Board under Contract 05-301. The statements and conclusions in this paper are those of the authors and not necessarily those of the California Air Resources Board. We are grateful to Caltrans staff at the Caldecott tunnel, Technical Services Division staff of the Bay Area Air Quality Management District, and California Air Resources Board staff for their assistance. We also thank Daniel Burgard, Donald Stedman, and Gary Bishop of the University of Denver and John McLaughlin of UC Berkeley. 


\section{References}

Ban-Weiss, G.A., McLaughlin, J.P., Harley, R.A., Lunden, M.M., Kirchstetter, T.W., Kean, A.J., Strawa, A.W., Stevenson, E.D., and Kendall, G.R. (2008). Long-Term Changes in Emissions of Nitrogen Oxides and Particulate Matter from On-Road Gasoline and Diesel Vehicles. Atmospheric Environment 42: 220-232.

Baum, M.M., Kiyomiya, E.S., Kumar, S., Lappas, A.M., Kapinus, V.A., and Lord III, H.C. (2001). Multicomponent Remote Sensing of Vehicle Exhaust by Dispersive Absorption Spectroscopy. 2. Direct On-Road Ammonia Measurements. Environmental Science and Technology 35: 3735-3741.

Buhr, S.M., Buhr, M.P., Fehsenfeld, F.C., Holloway, J.S., Karst, U., Norton, R.B., Parrish, D.D., and Sievers, R.E. (1995). Development of a Semi-Continuous Method for the Measurement of Nitric Acid Vapor and Particulate Nitrate and Sulfate. Atmospheric Environment 29: 2609-2624.

Burgard, D.A., Bishop, G.A., and Stedman, D.H. (2006a). Remote Sensing of Ammonia and Sulfur Dioxide from On-Road Light Duty Vehicles. Environmental Science and Technology 40: 7018-7022.

Burgard, D.A., Bishop, G.A., Stedman, D.H., Gessner, V.H., and Daeschlein, C. (2006b). Remote Sensing of In-Use Heavy-Duty Diesel Trucks. Environmental Science and Technology 40: 6938-6942.

Cadle, S.H., Nebel, G.J., and Williams, R.L. (1979). Measurements of Unregulated Emissions from General Motors' Light-Duty Vehicles. SAE Technical Paper Series no. 790694.

Cadle, S.H., and Mulawa, P.A. (1980). Low Molecular Weight Aliphatic Amines in Exhaust from Catalyst-Equipped Cars. Environmental Science and Technology 14: 718-723. 
Durbin, T.D., Wilson, R.D., Norbeck, J.M., Miller, J.W., Huai, T., and Rhee, S.H. (2002).

Estimates of the emission rates of ammonia from light-duty vehicles using standard chassis dynamometer test cycles. Atmospheric Environment 36:1742-1482.

Durbin, T. D., Miller, J. W., Pisano, J. T., Sauer, C., Younglove, T., Rhee, S. H., Huai, T., and MacKay, G.I..(2004). The Effect of Fuel Sulfur on $\mathrm{NH}_{3}$ and Other Emissions from 20002001 Model Year Vehicles. Atmospheric Environment 38: 2699-2708.

Emmenegger, L., Mohn, J., Sigrist, M., Marinov, D., Steinemann, U., Zumsteg, F., and Meier, M. (2004). Measurement of ammonia emissions using various techniques in a comparative tunnel study. Int. J. Environment and Pollution 22: 326-340.

EPA (2003). National Air Quality and Emissions Trends Report, 2003, Office of Air Quality Planning and Standards, Research Triangle Park, NC.

EPA (2006). Light-Duty Automotive Technology and Fuel Economy Trends: 1975 Through 2006, Office of Transportation and Air Quality, Research Triangle Park, NC.

Fischer, M.L., Littlejohn, D., Lunden, M.M., and Brown, N.J. (2003). Automated Measurements of Ammonia and Nitric Acid in Indoor and Outdoor Air. Environmental Science and Technology 37: 2114-2119.

Fraser, M.P., and Cass, G.R. (1998). Detection of Excess Ammonia Emissions from In-Use Vehicles and the Implications for Fine Particle Control. Environmental Science and Technology 32: 1053-1057.

Heavenrich, R.M., Murrell, J.D., and Cheng, J.P. (1987). Light-Duty Automotive Fuel Economy and Technology Trends Through 1987. SAE Technical Paper Series no. 871088.

Heywood, J.B. (1988). Internal Combustion Engine Fundamentals. McGraw-Hill, NY. 
Huai, T., Durbin, T.D., Miller, J.W., Pisano, J.T., Sauer, C.G., Rhee, S.H., and Norbeck, J.M. (2003). Investigation of $\mathrm{NH}_{3}$ Emissions from New Technology Vehicles as a Function of Operating Conditions. Environmental Science and Technology 37: 4841-4847.

Huai, T., Durbin, T.D., Younglove, T., Scora, G., Barth, M., and Norbeck, J.M. (2005). Vehicle Specific Power Approach to Estimating On-Road $\mathrm{NH}_{3}$ Emissions from Light-Duty Vehicles. Environmental Science and Technology 39: 9595-9600.

Kean, A.J.; Harley, R.A.; and Kendall, G.R. (2003). Effects of Vehicle Speed and Engine Load on Motor Vehicle Exhaust Emissions; Environmental Science and Technology 37: 37393746.

Kean, A.J.; Harley, R.A.; Littlejohn, D.; and Kendall, G.R. (2000). On Road Measurement of Ammonia and Other Motor Vehicle Exhaust Emissions; Environmental Science and Technology 34: 3535-3539.

Kirchstetter, T.W., Singer, B.C., Harley, R.A., Kendall, G.R., and Traverse, M. (1999). Impact of California Reformulated Gasoline on Motor Vehicle Emissions: Mass Emission Rates. Environmental Science and Technology 33: 318-328.

Moeckli, M.A., Fierz, M., and Sigrist, M.W. (1996). Emission Factors for Ethene and Ammonia from a Tunnel Study with a Photoacoustic Trace Gas Detection System. Environmental Science and Technology 30: 2864-2867.

Pearson, J., and Stewart, G.R. (1993). Tansley Review No. 56: The Deposition of Atmospheric Ammonia and Its Effects on Plants. New Phytologist 125: 283-305.

Pierson, W.R., and Brachaczek, W.W. (1983). Emissions of Ammonia and Amines from Vehicles on the Road. Environmental Science and Technology 17: 757-760. 
Seinfeld, J.H., and Pandis, S.N. Atmospheric Chemistry and Physics: From Air Pollution to Climate Change. John Wiley and Sons: New York, NY, 1998, pp. 74-75, 1056-1057.

Urban, C.M., and Garbe, R.J. (1979). Regulated and Unregulated Exhaust Emissions from Malfunctioning Vehicles. SAE Technical Paper Series no. 790696.

Watson, J.G., Chow, J.C., Lu, Z., Fujita, E.M., Lowenthal, D.H., Lawson, D.R., and Ashbaugh, L.L. (1994). Chemical Mass Balance Source Apportionment of PM10 during the Southern California Air Quality Study. Aerosol Science and Technology, 21:1-36. 


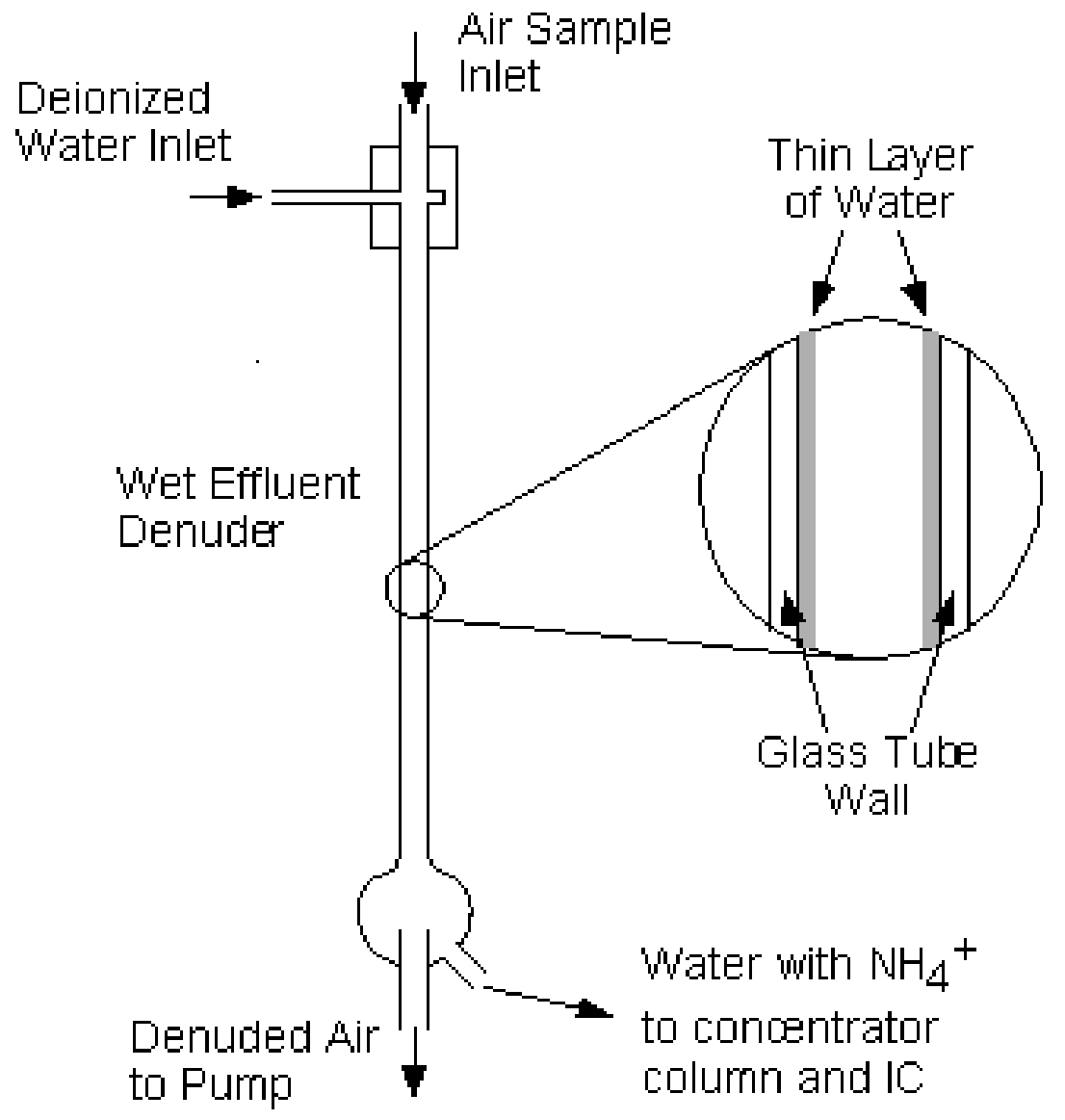

Figure 1. Schematic of the tubular wet effluent denuder used for ammonia sampling in 2001. 


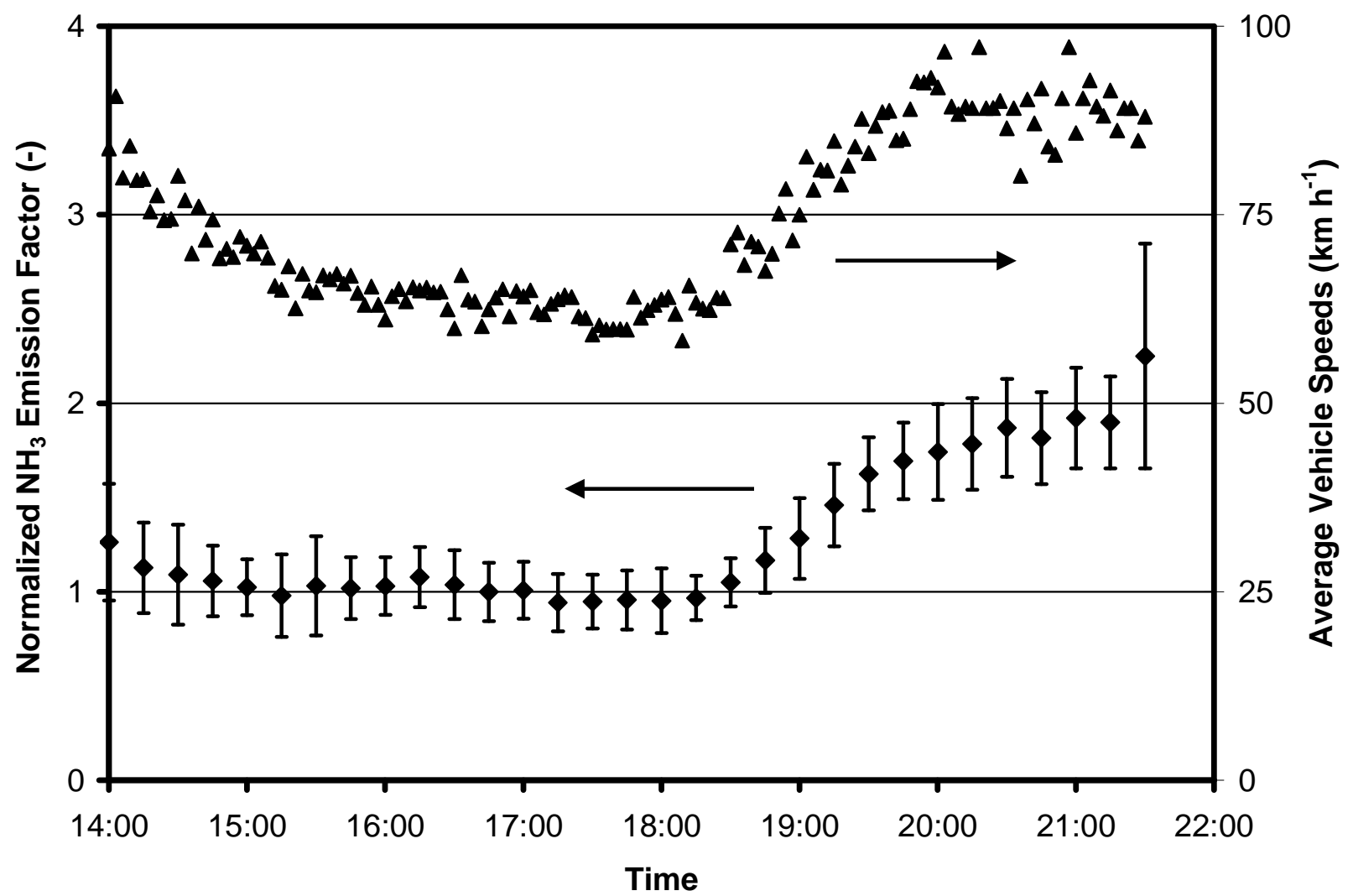

Figure 2. Average ammonia emission factors ( $\pm 95 \%$ confidence interval) for light-duty vehicle traffic driving uphill (plotted using diamond symbols) normalized by the average emission factor measured from 4-6 PM in summer 2001. Average vehicle speeds are also plotted (triangle symbols without error bars). 


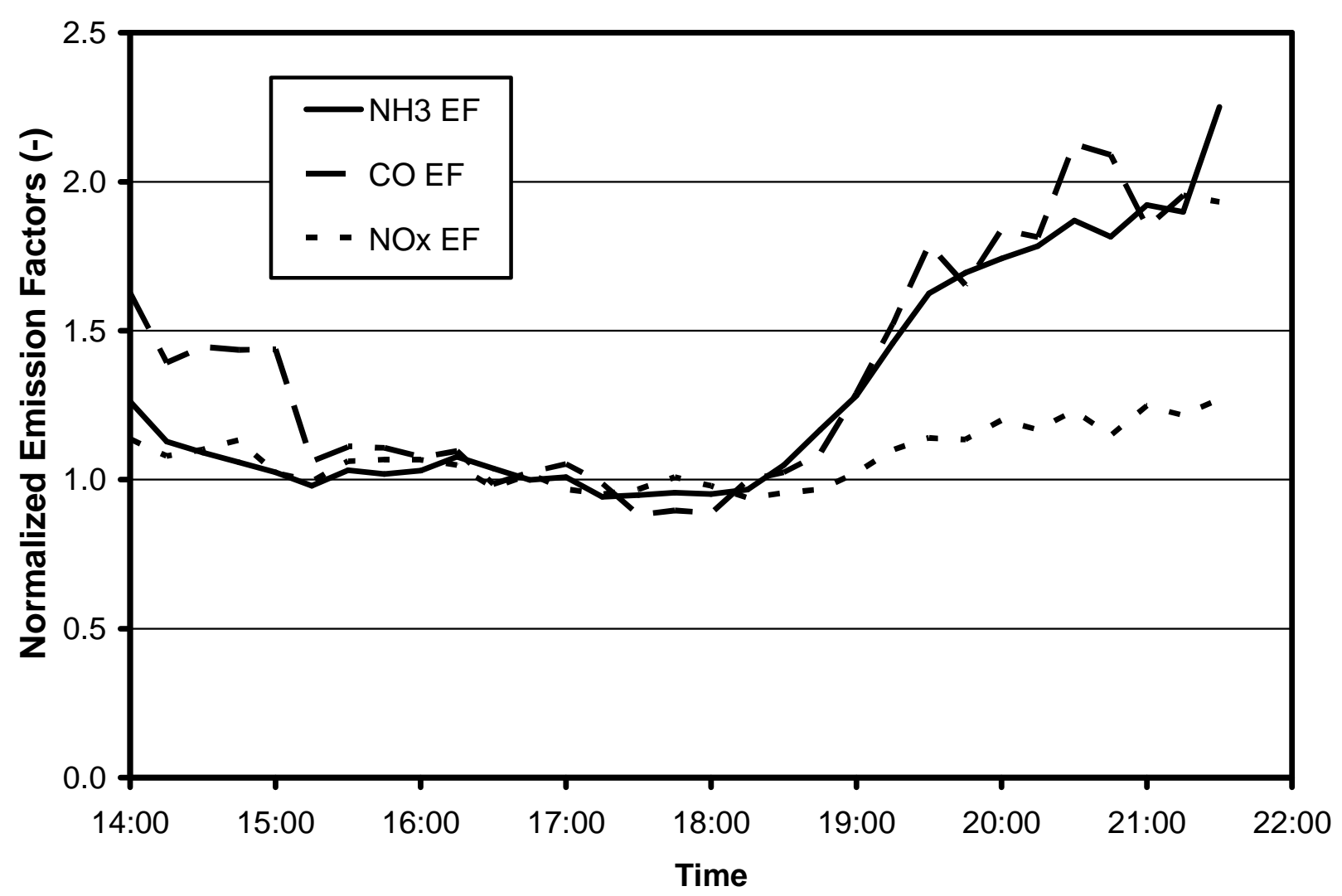

Figure 3. Emission factors for $\mathrm{NH}_{3}, \mathrm{CO}$, and $\mathrm{NO}_{\mathrm{x}}$ normalized by 4-6 $\mathrm{PM}$ average emission factors; measured over the entire tunnel-study in summer 2001 for uphill light-duty vehicle traffic only. 

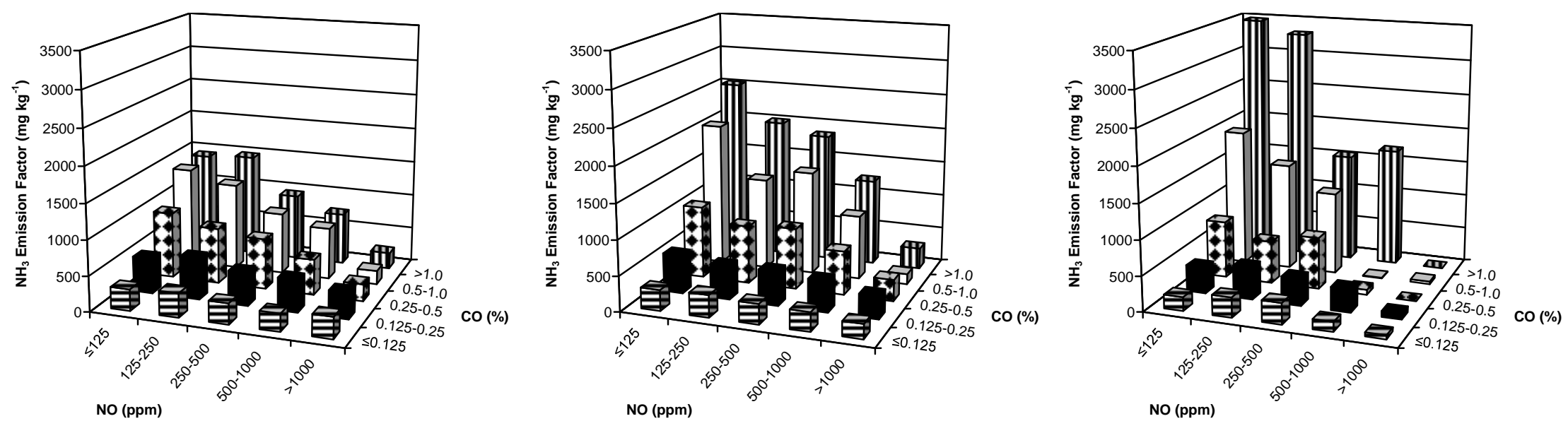

\begin{tabular}{|c|c|c|c|c|c|c|}
\hline \multicolumn{7}{|c|}{ Vehicles Per Bin } \\
\hline 232 & 126 & 110 & 124 & 129 & $>1.0$ & \\
\hline 148 & 78 & 97 & 103 & 147 & $0.5-1.0$ & $\%$ \\
\hline 244 & 107 & 139 & 123 & 130 & $0.25-0.5$ & $\stackrel{\circ}{\circ}$ \\
\hline 287 & 129 & 129 & 133 & 143 & $0.125-0.25$ & ¿ \\
\hline 469 & 162 & 184 & 207 & 212 & $\leq 0.125$ & \\
\hline$\leq 125$ & $125-250$ & $250-500$ & $500-1000$ & $>1000$ & & \\
\hline
\end{tabular}

(a)

\begin{tabular}{|c|c|c|c|c|c|c|}
\hline \multicolumn{7}{|c|}{ Vehicles Per Bin } \\
\hline 162 & 48 & 35 & 31 & 36 & $>1.0$ & \\
\hline 302 & 86 & 46 & 45 & 59 & $0.5-1.0$ & \\
\hline 744 & 174 & 117 & 79 & 50 & $0.25-0.5$ & \\
\hline 1393 & 265 & 202 & 126 & 63 & $0.125-0.25$ & 0 \\
\hline 2703 & 433 & 326 & 204 & 115 & $\leq 0.125$ & \\
\hline$\leq 125$ & $125-250$ & $250-500$ & $500-1000$ & $>1000$ & & \\
\hline & & NO (ppm) & & & & \\
\hline
\end{tabular}

(b)

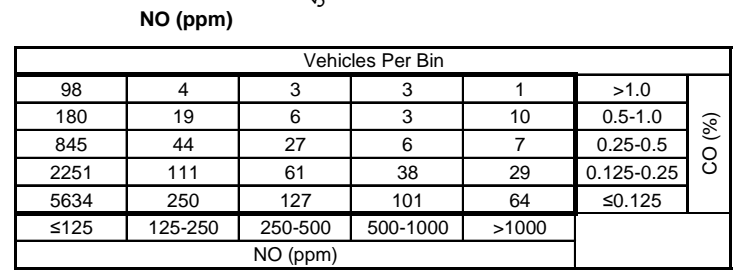

(c)

Figure 4. Average ammonia emission factors $\left(\mathrm{mg} \mathrm{kg}^{-1}\right)$ as a function of $\mathrm{NO}$ and $\mathrm{CO}$ concentration in light-duty vehicle exhaust

(calculated from Burgard et al., 2006a) for (a) model year 1995 and older vehicles (19\% of the 21,858 vehicles in their study were in this age group), (b) model year 1996-2000 vehicles (36\% of the 21,858 vehicles in their study were in this age group), and (c) model year 2001 and newer vehicles (45\% of the 21,858 vehicles in their study were in this age group). 


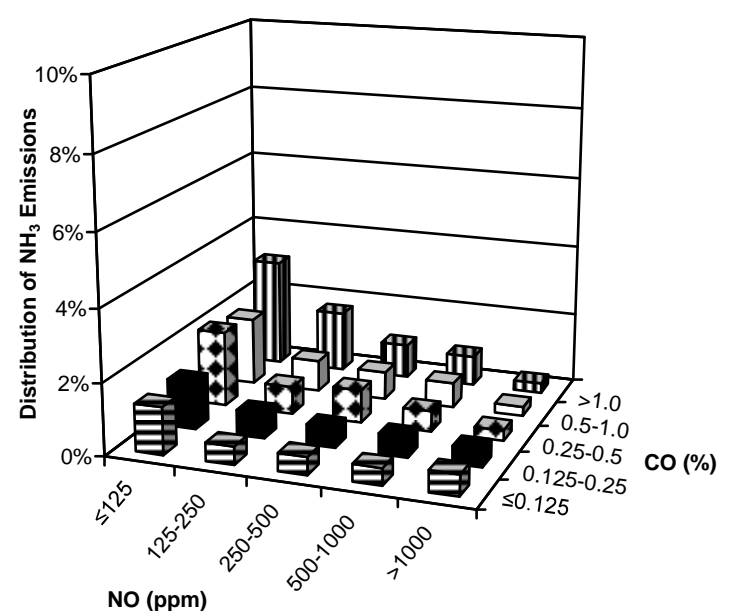

(a)

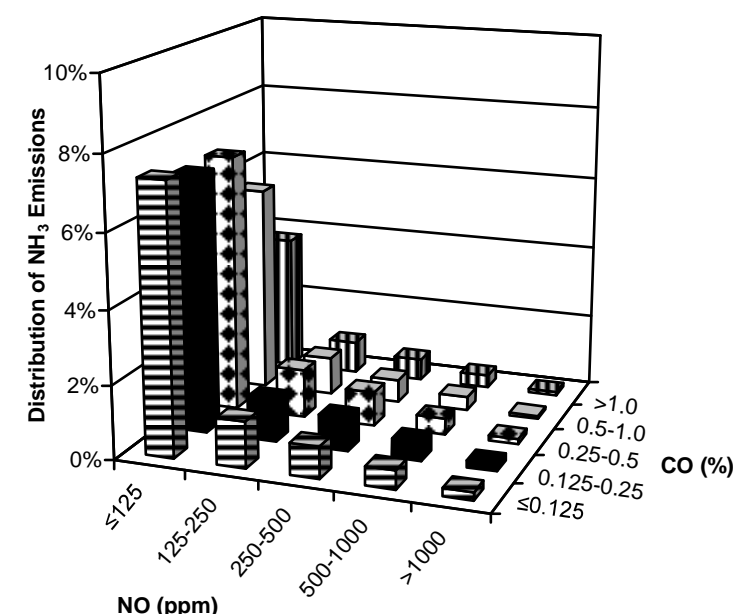

(b)

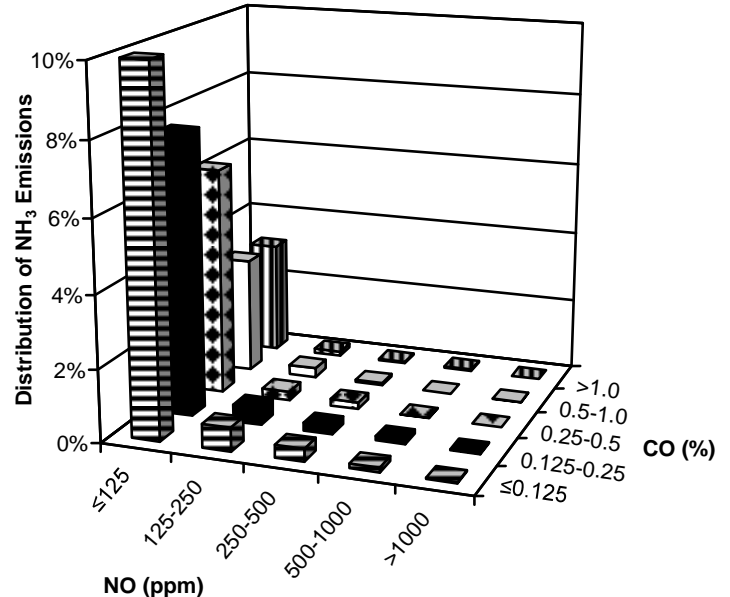

(c)

Figure 5. Estimated distribution of ammonia emissions at the measurement sites as a function of NO and CO concentration in lightduty vehicle exhaust (calculated from Burgard et al., 2006a) for (a) model year 1995 and older vehicles, (b) model year 1996-2000 vehicles, and (c) model year 2001 and newer vehicles. The bin heights in Figures 5a, 5b, and 5c sum to $100 \%$. 
Table 1. Comparison of On-Road and Recent Dynamometer-Based Ammonia Emissions Measurements from Light-Duty Vehicles.

\begin{tabular}{|c|c|c|c|c|c|}
\hline Year & Location & Authors & $\mathrm{mg} \mathrm{kg}^{-1}$ & $\mathbf{m g ~ k m}{ }^{-1}$ & Notes \\
\hline 1981 & Allegheny Mountain Tunnel, PA & Pierson and Brachaczek, 1983 & & $1.3 \pm 3.5$ & Very few $(<10 \%)$ three-way catalyst (TWC) equipped vehicles \\
\hline 1993 & Van Nuys Tunnel, CA & Fraser and Cass, 1998 & 510 & 61 & $81 \%$ of vehicles were TWC equipped \\
\hline 1995 & Gubrist Tunnel, Switzerland & Moeckli et al., 1996 & $230 \pm 70$ & $15 \pm 4$ & Authors have greater confidence in $\mathrm{mg} \mathrm{km}^{-1}$ than $\mathrm{mg} \mathrm{kg}^{-1}$ \\
\hline 1999 & Caldecott Tunnel, CA & Kean et al., 2000 & $640 \pm 40$ & $78 \pm 6$ & Warmed-up vehicles traveling at highway speeds up $4 \%$ grade \\
\hline 1999 & Freeway On-Ramp, CA & Baum et al., 2001 & $350 \pm 30$ & $37 \pm 3$ & Remote sensing study of warmed-up vehicles \\
\hline 2001 & Riverside, CA dynamometer & Durbin et al., 2002 & $420 \pm 140$ & $34 \pm 11$ & Mixed fleet of 39 vehicles on FTP driving cycle \\
\hline 2002 & Gubrist Tunnel, Switzerland & Emmenegger et al., 2004 & & $31 \pm 4$ & Investigation focused on comparing measurement techniques \\
\hline 2002 & Riverside, CA dynamometer & Durbin et al., 2004, Huai et al., 2003 & $\sim 120$ & $9-13$ & Dynamometer study of twelve $2000-2001$ vehicles on FTP cycle \\
\hline 2002 & Riverside, CA dynamometer & Durbin et al., 2004, Huai et al., 2003 & $\sim 680$ & $46-56$ & Dynamometer study of twelve $2000-2001$ vehicles on US06 cycle \\
\hline 2005 & Denver, CO and Tulsa, OK & Burgard, et al., 2006a & $500 \pm 10$ & & Remote sensing study of freely flowing highway traffic \\
\hline 2006 & Caldecott Tunnel, CA & Present investigation & $400 \pm 20$ & $49 \pm 4$ & Warmed-up vehicles traveling at highway speeds up $4 \%$ grade \\
\hline
\end{tabular}


Keywords: ammonia, NH3, emissions, trends, on-road, vehicle

\section{Corresponding Author:}

Andrew Kean

Mechanical Engineering

1 Grand Ave.

California Polytechnic State University

San Luis Obispo, CA 93407

805-756-1236

805-756-1137 (fax)

akean@calpoly.edu 